\title{
Chapter 17 \\ Psychodrama Practice in Clinical Social Work with Individuals
}

\begin{abstract}
This chapter is devoted to the clinical practice of psychodrama in individual sessions. Fundamental differences between psychodrama in groups and oneto-one contexts are discussed including the use of auxiliary roles, the therapeutic relationship, and modifications for basic psychodrama interventions. An overview of the use of the empty chair, objects, and/or the therapist as an auxiliary ego is included. The limitations and strengths of using psychodrama in individual sessions are discussed. Multiple psychodrama scenes (strengths-based, intrapsychic, and interpersonal) are depicted from a social work practice example with clinical processing.
\end{abstract}

Keywords Individual psychodrama - One-to-one psychodrama $\cdot$ Empty chair • Psychodrama a deux $\cdot$ Bi-personal psychodrama $\cdot$ Monodrama

This chapter will outline the use of psychodrama in individual psychotherapy and clinical social work settings. The processes described below will be focused on psychotherapy, but are also applicable in individual supervision, coaching, and consulting sessions. Psychodrama with individuals, sometimes called bi-personal psychodrama, monodrama, one-to-one psychodrama, or psychodrama a deux, has both its limitations and its benefits when compared group psychodrama in groups. Some find Moreno's methods to be more easily integrated by practitioners in individual settings than group settings. There are uniquely different clinical concerns with the process of psychodrama work with individuals as opposed to group work. Considerations for individual psychodrama work, including the therapeutic relationship, doubling, mirroring, role reversal, and auxiliary roles will be explored. And finally, a psychodrama case will be presented with multiple psychodrama sessions to depict the unique aspects of psychodrama in individual sessions.

\subsection{Providing Context for Psychodrama in Individual Sessions}

The use psychodrama in individual sessions is based on the same foundational philosophy and interventions outlined throughout this book. Nearly all of Moreno's

S. Giacomucci, Social Work, Sociometry, and Psychodrama, Psychodrama in Counselling, 
psychodramatic theories are applicable and easily adaptable for conceptualizing psychodrama work with individuals (von Ameln \& Becker-Ebel, 2020). The process remains mostly the same in terms of the phases of warming up, enactment, and processing; however, there are no role players. The primary difference between individual sessions and group sessions is the context. In the one-to-one psychodrama context, each of the five primary instruments of a classical psychodrama (see Sect. 6.5) are modified - the director, the protagonist, the stage, the auxiliaries, and the audience (Aguiar, 2019; Hirschfeld \& McVea, 1998).

Group sessions take place with a group and usually are scheduled as longer sessions than individual appointments. While a psychodrama group generally employs a psychodramatic enactment in every session, this is not the case with individual work. Individual psychodrama practitioners usually integrate psychodrama enactments, written sociometric/psychodramatic processes, traditional talk therapy, and often other structured therapeutic approaches (such as art therapy, cognitive behavioral therapy, and eye-movement desensitization and reprocessing) into their sessions. Though Moreno's group psychotherapy and psychodrama model emerged from his opposition of psychoanalysis, practitioners employing psychodrama in individual sessions seem much more likely to also integrate psychanalytic and psychodynamic theories into their work. Another logistical concern is the physical space in the individual therapy room, which is generally much more restrictive than the space of a group room. The stage for the one-to-one psychodrama may need to be reconsidered in creative ways making use of the space available (Aguiar, 2019).

Group psychodrama sessions seem to be held across the treatment continuum, from inpatient and residential treatment centers, partial programs, intensive outpatients, private practices, and multiday workshop intensives. On the contrary, one-toone psychodrama sessions seem to primarily be utilized in outpatient private practice settings. Though the 50-60 min session length seems to be the norm in outpatient work, it may be advantageous to schedule longer sessions when a psychodrama is expected (Chesner, 2019a; Fonseca, 2019). Chesner (2019a) notes that while group psychodramas focus on one topic following a Psychodramatic Spiral to closure with the session, individual psychodramatic work often follows a longer arc as one topic can extend through several sessions with psychodrama scenes dispersed among sessions. She compares a group session to an immersive two hour movie and individual work to a television series with weekly episodes_- "while a group session is like a feast with many courses, which requires time to digest, the one-to-one frame offers regular bite-sized therapeutic nourishment" (Chesner, 2019a, p. 12).

\subsubsection{The Therapeutic Relationship}

Perhaps one of the larger differences between group work and individual work is that in group work the group is the client while in individual work, the individual is the client (Moreno, 1947). Yalom and Leszcz (2005) write that group cohesion in group work is analogous to the therapeutic relationship between clinician and 
client in individual work. In individual work, there is no group-thus no group cohesion exerting its healing influences upon the individual. Instead, the working relationship between client and clinician is elevated in importance. The primary role of the social worker in a group is to help participants access the healing power of mutual aid between participants, but this is not applicable in individual workinstead, the social worker must take a much more active role as a participant in the therapeutic dyad. The use of self, direct suggestions or advice giving, feedback, and analysis from the therapist play a more centralized role in individual work because the group is not present to fulfill some of these functions. Aguiar (2019) writes that "one of psychodrama's most revolutionary proposals was attributing the therapist role to all of the group members" becomes null in the therapist-client dyad where roles are clearly defined with rank.

Antonio (2019) and Kim (2019) highlight the increased relevance of the encounter, tele, transference, and countertransference within the therapeutic relationship in one-to-one psychodrama contrasted to group work. Moreno's encounter philosophy suggests that the self only exists in relationship to others. The client role only exists through the role reciprocity of client-therapist. In one-to-one psychodrama, the multiple layers of role relationships between client and therapist become more conscious, while in group work, the role relationships between participants are more in focus. Moreno (1959) conceptualizes transference as a function of role relationships; Bustos (1979) adds that transference is characterized by a loss of spontaneity and increased anxiety within the dyad. In the process of individual work, the presence of transference and countertransference between client and therapist are much more explicit, expected, and significant to the therapeutic process. The blend of playfulness and intensity that the client experiences in a psychodrama may lead to an increased chance of transference emerging, especially when the therapist is interviewing the client playing a different role (Bustos, 2019). Similarly, the intensity of the psychodramatic process and the role demands of being a therapist may activate a therapist's countertransference which would interrupt tele (Kim, 2019). Moreno writes that underneath transference exists a telic relationship as an accurate twoway connection between individuals which is essential to a successful therapeutic relationship $(1959,1972)$. Tele is conceptualized as a fundamental ingredient in any healthy interpersonal relationship characterized by spontaneity, especially between client and therapist. Ongoing assessment and awareness of tele, transference, and countertransference in the therapeutic dyad provide a balanced attunement to both the psychodynamics of the client and therapist, as well as the sociodynamics of the relational space.

\subsubsection{Limitations to Individual Psychodrama Work}

There are various limitations to using psychodrama in individual settings. One of the largest limitations is the lack of a group and auxiliaries to play the roles needed for psychodrama enactments. While the other psychodrama roles can be concretized 
with objects or empty chairs, there is an interactional element lost when the role is not being played by another human being. The absence of an audience means that the only person that can offer doubling statements is the therapist. In group psychodrama, physical touch is often an important element between group members-most often through a hand on the shoulder when choosing a topic, doubling, or offering support, a supportive hug when needed, or other physical contact between roles in the scene (Giacomucci, Gera, Briggs, \& Bass, 2018). Therapists are much more restricted in their physical touch with a client than group members are which significantly limits opportunities for the client in individual psychodrama sessions to experience safe and supportive touch (Chesner, 2019a).

The intensity of role reciprocity, tele, and spontaneity is decreased between roles due to the absence of human role players. The multiplicity of human relationships in the group is also relied upon by the psychodrama director in the process of cocreating the psychodrama enactment. Brito (2019) describes the implications of this in the following passage:

As opposed to what usually happens in larger groups, in one-to-one psychodrama the subjectivity of the therapist is more directly involved in the establishment of the protagonic climate. In larger groups this originality is diluted in the complexity of relational possibilities of the other therapeutic agents. Restricted to the role of the director, the therapist relies on the other members of the group as auxiliary egos to facilitate the development of the dramatic project. (p. 23).

The one-to-one psychodrama enactment is void of the additional therapeutic agents present in a group psychodrama enactment. Because of this fundamental difference, the therapist must become more involved as a therapeutic agent and place more reliance on the concretized roles as agents in the therapeutic process.

The absence of a group also decreases the sense of universality and the ability for mutual aid between participants. The group member's process of using their own experience to help another group member is empowering, healing, and therapeuticthis possibility is mostly lost within the therapeutic dyad. The social dynamics of a group often lead to what Yalom calls the corrective recapitulation of the primary family group, which is still present in individual work, but not with the same number of possibilities. Other therapeutic factors remain present, but become diminished in individual work including social learning, instillation of hope, imparting of information, altruism, socializing techniques, imitative behavior, interpersonal learning, and group cohesion. Each of these factors in group work emerge in the constellation of sociodynamics between multiple group members but lose some of their effect in the dyad. In the group, there are a multiplicity of relationships from which these factors materialize, but in the therapeutic dyad, they can only exist between therapist and client.

Individual work also does not offer the possibility for the client to be in the role of an audience member or auxiliary role for someone else's psychodrama. Both of these roles in group psychodrama provide unique learning perspectives for clients and role relief from being the center of attention. Moreno (1972) highlights that catharsis has an interpersonal nature, which loses its potential in individual work as well. There are unique cathartic and integrative phenomena that a participant only experiences 
through the role of an audience member or auxiliary role. The individual client is always the center of attention in individual work. Every psychodrama that takes place through individual psychotherapy places the client as the protagonist. This aspect may be considered both a limitation and a benefit of one-to-one psychodrama work. Another limitation that exists in one-to-one psychodrama work is the lack of group sharing after an enactment which often leads to new insights and integrations.

A larger limitation to the practice of psychodrama in individual work is the lack of formalized training offered in this specific context (Brito, 2019). Most formal psychodrama training programs orient themselves on Moreno's triadic system of sociometry, psychodrama, and group psychotherapy. As such, psychodrama is almost always categorized within the larger group work field without much attention given to its utility in individual sessions. The psychodrama field would benefit from increased attention to the needs of individual practitioners learning one-to-one psychodrama.

\subsubsection{Strengths of Individual Psychodrama Work}

Beyond the aforementioned limitations, there are also multiple strengths inherent to the one-to-one psychodrama process. The therapist does not need to maintain awareness of multiple group members which means that the individual psychotherapy client will experience much more attention from the therapist. The therapist's attunement to the client is uninterrupted by the needs of other group members or the groupas-a-whole. This attunement to the client also translates to a warming up process and topic selection that is client-centered rather than group-centered. The risk of an individual client's topic not being chosen or individual clients being at varying levels of warm-up to a topic is eradicated in the individual psychodrama process. As mentioned previously, the client in individual therapy is always the protagonist in the psychodrama which has its benefits. Every psychodrama in individual therapy is relevant to the protagonist and meets them where they are at in terms of warm-up, clinical issues, ego strength, and willingness.

The ongoing nature of individual work with clients makes it easier to build upon previous sessions and resume psychodramatic work on clinical issues from previous sessions. This becomes more complicated in a group as the facilitator must balance the wants and needs of every client in a fair manner. While group psychodrama sessions often have topics that vary from session to session, individual psychodrama sessions can afford more continuity and follow-up on topics. The psychodramatist can more readily meet the individual client where they are at in each session modifying the pace, topics, and processes in attunement with the client. For all of these reasons, individual therapy may feel less threatening and safer for clients to engage in than group work. In the one-to-one psychodrama context, both the therapist and client have significantly more control of the process than they would in a group setting. 


\subsection{The Double, Mirror, and Role Reversal in Individual Psychodrama}

The interventions of doubling, mirroring, and role reversal were developed specifically in the group psychodrama context and each is modified for individual psychodrama work. In the group setting, other group members often step into the double role and/or offer doubling statements which contribute to the protagonist's expression of emotion, support from the group, and sense of identification with the participants. In the one-to-one psychodrama situation, the only person available to double is the therapist. In some ways, the double position is the best place for the therapist due to their insight and understanding of the client's clinical issues. The utilization of doubling by the therapist both relies on the therapeutic relationship and enhances it through the client's sense of being understood by their therapist. It is suggested that the therapist reflects on the use of doubling in their individual work as to avoid overusing it and potentially being experienced as controlling by the client (Chesner, 2019b).

The mirror position is also useful in one-to-one psychodrama but relies more on the imagination and surplus reality as there are no role players to re-enact the scene while the client watches from the mirror position. Instead, the client is instructed to move into the mirror position, and using objects to concretize roles from the scene, the client is invited to imagine the enactment from this place of observation and distance. The mirror position can be helpful for discerning choices, enhancing clarity, containing emotion, accessing cognition, and cultivating integration for the client. It can also be useful in difficult moments between the client and therapist as it provides the distance to obtain clarity and intervene on transferential dynamics or misunderstandings. If the therapist notices that the client is in the mists of transference with the therapist, from the mirror position they could use concretization to differentiate therapist and the person or role being projected upon them. Transferences can be worked out psychodramatically in this way.

The role reversal in one-to-one psychodrama is fundamentally the same as it is in group work, but without a role player in the other role. If trained auxiliaries are available, they can be helpful for conducting psychodramas in individual sessions as the role reversals and role-playing are more embodied. Though in most cases, it becomes financially unreasonable to work with trained auxiliaries. Without role players in psychodrama, the client is asked to role reverse and speak to objects or empty chairs that have been designated to concretize the other roles. When returning to the role of self, they can be invited to imagining that they are hearing and receiving the message from the role of the other. This process of role reversal keeps the psychodrama more contained, which is advantageous in some situations but a limitation in other situations. 


\subsubsection{Therapist as Auxiliary Roles?}

There is ongoing debate about the appropriateness of the therapist taking on auxiliary roles in psychodramas with individual clients (Aguiar, 2019; Antonio, 2019; Brito, 2019; Cukier, 2008; Figusch, 2019; Fonseca, 2019; Knittel, 2009). A major crux of the dilemma is based upon the tradition of therapists upholding power dynamics between the roles of therapist and client by avoiding personal involvement. A therapist playing auxiliary roles needed in the client's psychodrama scene has a very active involvement in their work. Brito (2019) frames it as, "the dilemma of how to co-act, co-create and co-experience without 'mixing' with the patient" (p. 26). There are, of course, professional boundaries that a social worker upholds in the therapeutic dyad. And, at the same time, it seems that social workers in general might be more willing than other professionals to mix with their client in co-acting, co-creating, and co-experiencing. Theoretically, the dilemma touches upon the question of whether or not the psychodrama session is treated as a group of two people (therapist and client) or as an individual therapist and individual client (Brito, 2019). It seems therefore that those who approach one-to-one psychodrama as a group of two will be likely to play auxiliary roles. On the contrary, those who maintain the traditional view of the session being two individuals would be more likely not to play auxiliary roles and to maintain their individual role of therapist/director. There are, of course, benefits and limitations to each approach.

The biggest benefit to the therapist playing auxiliary roles is an enhanced psychodrama enactment with more interaction and production between roles and between the therapist and client. The role reversal experiences become especially more real when another person is playing the roles. The therapist becomes a more active participant in the process rather than a facilitator outside of the scene. The playing of roles by the therapist could contribute to a client's sense of being joined in the drama. The enactment between client and therapist in new roles offers opportunities for a deepening of the therapeutic dyad. A skillful and experienced psychodramatist can facilitate the enactment by shifting between the director role and an auxiliary role and even passively directing the scene from the auxiliary role. By playing a role in the client's psychodrama, the therapist is likely to gain increased insight into the nature of the client's relationships. It is also likely that the therapist will experience therapeutic benefits and personal growth of their own through the engagement as an auxiliary ego. When choosing to play roles, the therapist would be wise to specify which types of auxiliary roles would be therapeutic for them to play and which would not be. For instance, they might choose to engage as an auxiliary in strengths-based and supportive roles, but decline playing antagonistic or perpetrator roles from the client's life.

There are also limitations to the therapist choosing to play auxiliary roles in the client's psychodrama. The directing of the psychodrama becomes more difficult and complicated when the therapist is playing a role and trying to be both an auxiliary and a director. In doing so, they may lose their objectivity and thus their ability to 
direct the scene with minimal bias. The therapist's ability to offer doubling statements is also compromised if they are playing an auxiliary role in a scene. There is an increased potential of losing role clarity when the therapist is shifting between the roles of director, auxiliary, and double (Chesner, 2019b). Auxiliary role-playing by the therapist also increases the possibility of the therapist's use of self being overused through the auxiliary role or their own emotional material and countertransference becoming activate in the psychodrama. The likelihood of client transference and projections upon the therapist increases especially if the therapist plays an emotionally charged role in the client's psychodrama and the client is unable to fully de-role them (Hirschfeld \& McVea, 1998). Being that the therapist is the recipient of the client's transference and projection from the role they played, they will have more difficult shifting back into a director role and de-roling. Chesner (2019b) suggests that the here-and-now space of the client-therapist dialogue should be physically different than the surplus reality space of the psychodrama enactment to increase role clarity and de-roling abilities.

The question of therapists playing auxiliary roles is one that each therapist will need to respond to when facilitating one-to-one psychodrama sessions. It may be a question that permits different answers based on the varying needs, ego strengths, and relationships with each client. It is suggested that the therapist engages in a reflective process and discerns which approach may be best for their clients. The following vignette will depict one-to-one psychodrama with a therapist choosing not to play auxiliary roles.

\subsection{A One-To-One Psychodrama Scenes Throughout the Treatment Process}

The following subsections will depict different one-to-one psychodrama vignettes with Mary, whose social atom was included in Sect. 16.1. The development of her social atom helped warm her up to new work around grief and loss, as well as childhood trauma. The social worker slowly began to introduce psychodramatic interventions into their individual therapy sessions. Short psychodrama vignettes with strengths-based roles were introduced to set the foundation for later scenes. The first vignette below depicts a strengths-based scene, the second vignette describes an intrapsychic psychodrama scene, and the third vignette offers a portrayal of an interpersonal one-to-one psychodrama. The exploration of a single case over time shows the utility of individual psychodrama work and its unique potential to build upon past psychodramas in a linear manner. 


\subsubsection{Strengths-Based Scenes}

The social worker first ensures Mary's consent, permission, and warm-up to engage in a psychodrama vignette. When asked which strengths she would need to heal from her trauma, loss, and work through her anxiety and depression, Mary indicated that she would need more courage. The social worker invites Mary to choose an object in the room to represent courage, and she chooses the painting on the wall. The therapist invites her to role reverse with courage-becoming courage. Mary steps into the role of courage, standing in front of the painting and begins speaking to herself as if she were still sitting on the couch.

MARY AS COURAGE: Hi Mary, remember me? You used to use me so much in your life, but we have not been so close lately.

THERAPIST: Courage, can you remind Mary of some of the times she did use you throughout her life? remind her of the times that you were close.

MARY AS COURAGE: Well... Mary, I know it is difficult for you to talk about things in your life so I help you do that... (Mary appears stuck).

THERAPIST: Courage, is it okay if I offer a doubling statement for you? If it is accurate you can repeat it to Mary, if it does not fit, you can simply change it to make it fit for you.

MARY AS COURAGE: Okay.

THERAPIST AS DOUBLE: Mary, you have a lot more courage than you realize. You use me (courage) every time you come to therapy.

MARY AS COURAGE: (a soft smile emerges as her body loosens up) Mary, you have way more courage than you can see right now. Every time you come to therapy, you use me.

THERAPIST: (steps out of double role) Yes. That is right, every time Mary comes to the office here, she brings you. Seems like you are a pretty important part of Mary. Tell her more about you and how she can connect with you.

MARY AS COURAGE: When you feel scared to do something, I am what helps you push through and do it anyway Mary. I have helped you have meaningful relationships, a successful marriage, to ask for help, to thrive as a woman in your career, to survive your childhood, and to live a good life. You might not realize it, but I am an important part of you. I'm especially important now because I can help you walk through your anxiety and depression. When you feel scared or stuck, just tap into me.

THERAPIST: Can you tell Mary how she can tap into you?

MARY AS COURAGE: You can tap into me by standing up proudly, taking a few deep breathes, and remembering the many other times you have been courageous in your long life. 
THERAPIST: Great job courage. Go ahead and reverse roles.

(Mary moves back to her place sitting on the couch).

THERAPIST: Okay, Mary, just take a minute to look over here at courage (pointing to the painting on the wall) and take in all those messages and reminders of your courage - especially the advice on how to tap into courage. When you are ready, lets practice implementing the advice from courage about standing proudly, taking deep breathes, and remembering past experiences of courage.

Mary stands up, takes a few deep breathes and closes her eyes. As she recalls previous moments of courage, her posture and facial expression begin to depict confidence and courage. She begins to smile gently, opens her eyes, and comments on how surprised she is about her current sense of courage. Following the enactment, Mary and the therapist organically shift into a reflective discussion about the scene.

In the sharing phase of the one-to-one psychodrama, the therapist shares more of themselves, while maintaining their professional boundaries (von Ameln \& BeckerEbel, 2020). This is a time for the Mary to cool down from her psychodrama experience and to integrate the learning from the enactment. In the ongoing individual psychotherapy context, this is the time for the therapist and Mary to also discuss a concrete plan for how she will implement their new learning in between sessions. Mary agrees to take time each day to practice standing proudly and taking deep breathes while remembering memories of courage.

Having completed this strengths-based psychodrama above, every time Mary returns to the office, she sees the painting on the wall and is reminded of her courage. This may happen unconsciously or consciously-and the therapist now has another strengths-based tool to weave into future sessions. In subsequent sessions, Mary completes similar strengths-based psychodrama vignettes using the office plant to symbolize compassion for self, the lamp to represent her hope, the clock to play the role of her future self no longer stuck in depression or anxiety, and the pillow to represent God. With each journey into surplus reality, Mary increases her level of connection to the therapist, her trust and familiarity with the psychodramatic method, and her psychological stability or ego strength. The office becomes inherently resourcing after a few psychodrama sessions as Mary experiences the positive projections with the previously chosen objects in each session. Every time she walks back into the space of the office, she is greeted by her strengths and reminders of previous therapeutic successes through psychodrama.

\subsubsection{Intrapsychic Scene}

Having spent time resourcing her with strengths-based roles and enhancing the therapeutic relationship, Mary becomes more willing to share and be vulnerable with the therapist over time. She begins to talk about feeling stuck in anxiety and depression and that there is a part of her that just wants to stay stuck and be taken care of by others. She describes it as an old feeling that resembled her experience as a child with 
a depressed father and an abusive mother that were not always able to adequately fulfill her developmental needs. Mary and her therapist schedule a longer session with the intent of doing a more intensive internal psychodrama scene exploring her relationship with a wounded/younger self role. The psychodrama scene begins with an integration of the strengths from previous enactments with a focus on their utility for today's topic. Mary is instructed to reverse roles and offer a statement to herself from each of the roles of courage, self-compassion, hope, future self, and God.

MARY AS COURAGE: You have the courage to explore your past and heal from it. You can do it!

MARY AS SELF-COMPASSION: I am so proud of you for the work you are doing to better yourself. You are a good, kind woman.

MARY AS HOPE: Mary, although your depression, anxiety, loss, and trauma may seem overwhelming at times, none of it has to define you today. You can heal from it and work though all of it, one step at a time.

MARY AS FUTURE SELF: Though you are unsure about today's psychodrama, trust me when I say that it will be worth it.

MARY AS GOD: I am with you always. You are perfectly imperfect-I created you in this way so you could walk this unique path that I have laid out for you. This is the next step today.

After giving voice to supporting message from each of these strengths-based roles, Mary returns to her own chair and is encouraged by the therapist to take a moment to ground herself in the support and presence of all of her strengths-based roles. Then, the therapist pulls out an empty chair and instructs Mary to imagine that her wounded self is in the empty chair. When working with trauma-based roles in individual work, it is often best to avoid concretizing them with objects in the room as it could encourage negative projections in future sessions when the client sees the same object.

THERAPIST: Mary, here is the part of yourself that did not get her needs met as a child and was hurt and neglected by her parents at times. Perhaps this is the same part of yourself that today feels paralyzed with depression and anxiety. What is it you need to say to this part of yourself?

MARY: I know how hard it was for you growing up and that at times it felt like nobody cared about you. I know you felt stuck and afraid-that you think you are trapped forever in this situation. It is okay. You did the best that you could and I am so happy you survived and got out of that family. I know you still exist within me because I can feel your pain and your anxiety all the time. I just want to find a way so you don't have to hurt so much.

THERAPIST: Great job Mary. You are really using that strength of self-compassion here. I am wondering if there are other strength roles that have anything to say this hurt part of you? 
MARY: Yes, I think wounded Mary needs to talk to hope.

THERAPIST: Okay, reverse roles with hope. What do you have to say to wounded Mary?

MARY AS HOPE: (speaking to wounded Mary) Hi Mary, I know you feel hopeless sometimes but I am here to remind you that thinks will get better. There is always hope. Don't give up on yourself. This is all just temporary, and you have a good life ahead of you.

THERAPIST: Go ahead and role reverse with wounded Mary. From this role, can you articulate the feelings and thoughts you experience?

MARY AS WOUNDED SELF: I just feel so trapped and stuck all the time. I don't feel like trying sometimes - would rather someone else take care of things for me. It is so unfair that I have to deal with all this loss, depression, and anxiety. My life has been hard enough. I feel so shameful for having these problems. I am afraid that things won't get better and instead they will just get worse until I die.

THERAPIST: Is there more that you need to say? It sounds like you have been neglected for a long time and have accumulated a lot of hurt over the years... What haven't you been able to say about your parents?

MARY AS WOUNDED SELF: Well, yeah. I am so angry at my mom for how she treated me and upset that my dad never gave me attention and love when I wanted it. I was just a kid and they were supposed to love me. I had to grow up so early and figure out how to take care of myself. (Mary begins to cry) I still hear the voice of my mom shaming my dad for being depressed. She always told him to stop being selfish and to suck it up. She thought depression wasn't real, and so did I. I can imagine my mom saying the same things to me today because of my depression. I feel worthless when I think about it.

THERAPIST: You have waited a long time to express these feelings Mary, just let them out here. What else is there?

MARY AS WOUNDED SELF: (Mary continues tearfully) I just feel so upset with myself. How did I end up so stuck and depressed? I feel like I've wasted so much of my life and I hate myself for it.

THERAPIST: Sounds like you are really hurting here. I'm wondering what Mary's relationship with you has been like?

MARY AS WOUNDED SELF: She ignores me and pretends that I don't exist, or she shames me for the feelings I have.

THERAPIST: Can you tell her what it is that you need from her?

MARY AS WOUNDED SELF: Mary, I need you to pay attention to me. Stop ignoring me or shaming me for how I feel. You are doing the same thing that Mom did to Dad. I need your help or we both are going to be stuck. Will you help me? 
THERAPIST: Reverse roles. Mary, you've heard everything this wounded part of yourself has to say, she is asking you to help her, pay attention to her, and stop shaming her. How do you want to respond?

MARY: (begins to cry) Mary, I'm so sorry that I've treated you like this for so long. You have already been through so much and you deserve better...

THERAPIST: Don't forget that all of your strengths are here to help you with this too Mary.

MARY: (looks around the room remembering her strengths. Then she stands up, takes a few breathes and steps closer to the empty chair containing her wounded self) Mary, I'm sorry for shaming you for your feelings. I'm sorry for ignoring you. I see how much you are hurting, and I am going to take care of you from now on. I can see why you felt so stuck and hopeless. I was afraid of your feelings and afraid of accepting you. I'm going to give you the love you deserve. You are a precious part of me, and I am going to treat you like that going forward.

THERAPIST: As we move towards closure Mary, I wonder if there is a commitment you can make to yourself about something concrete you can do to put this love into action?

MARY: I am going to commit to you that I will take time to journal about you at least twice this week. If it is helpful, then I will make it a regular habit to write about you.

THERAPIST: I think that is a great commitment and a good plan for implementing this work into your life going forward. You can use the psychodramatic letter writing and psychodramatic journaling tools that I've shown you previously.

From here, the therapist and Mary de-role the empty chair and transition to the sharing phase of the psychodrama process. Mary expresses her experience as the protagonist while remembering the different roles and dialogues she just engaged in. She comments on how helpful it was to have the strength roles present and that she does not know that she would have been able to have the discussion she had if it were not for her courage, hope, and self-compassion. The therapist frames this inner scene between her, her strengths, and her wounded self as an ongoing dialogue that will continue within her beyond this session. The therapist celebrates Mary's work today while also reminding her that it will take practice and consistency to change the internalized messages that she has been carrying with her for several decades.

In psychodramatic terms, Mary has accessed the spontaneity to change her intrapsychic relationship with this part of herself. She responded to in a new and adequate way while creating a new cultural conserve for a more accepting in loving relationship with herself. Now that she has engaged in the strengths-based work and internal work, she is more prepared for the interpersonal psychodrama that is to come. 


\subsubsection{Interpersonal Scene}

Based on Mary's ongoing clinical work, it became clear that she had unresolved issues with her mother. This was apparent in her social atom depiction (see Sect. 16.1), within which her deceased mother was nearly the same size as her husband and her depression/anxiety. The previous, intrapsychic psychodrama enactment revealed the internalized shame that Mary carries about having depression and anxiety because of her mother's comments to her depressed father. She describes a common situation to involve her father watching television on the couch, while her mother yells at him for being lazy, depressed, and a poor husband. Mary describes how as a child, she would hide in her room during these instances and wait for it to be over, wishing that her father would stand up for himself. Mary and her therapist set an intention to engage in a psychodrama enactment to work through some of the unfinished business with her mom.

When Mary arrives to the session, the therapist instructs her to connect with her strengths by role reversing with each and offering herself a message of support. The messaging from her strengths and supportive roles fortifies her and affirms her commitment to moving forward with the clinical contract. Mary is invited to recreate the scene described above using pillows or chairs in the office to represent her mother, father, and herself as a child. From the mirror position, she is asked to describe the scene, including the messages and actions of each person. The therapist, having assessed her as emotionally capable of re-experiencing the scene, directs her to step into the role of her mother.

THERAPIST: Mom, what is it that you feel about your husband here, tell him.

MARY AS MOM: You are pathetic. You barely can hold a job because you call out all the time and stay home watching television. I can't believe you. This depression is all in your head. You need to snap out of it and act like a man before I leave you.

THERAPIST: Sounds like you are pretty angry that he can't just be normal?

MARY AS MOM: Yeah, I'm furious at him. I have to work twice as hard around the house and at my job in order to pick up the slack.

THERAPIST: Are you afraid that he will lose his job? Sounds like his depression has created additional burdens for you. Can you give us an internal soliloquy of mom?

Mary AS MOM (soliloquy): Of course. I'm afraid he will lose his job and how it will impact our family. I feel like I am the only adult in the home, and I have to take care of him too. It's not fair. I'm upset that my husband isn't able to be fully present with me. I feel stuck in this situation too.

THERAPIST: Okay. Mary-reverse roles with your father. Now, show us how you respond to your wife.

MARY AS FATHER: (lays on couch with detached expression—says nothing).

THERAPIST: You have nothing to say huh? 
MARY AS FATHER: What's the point. Nothing I say or do will be good enough.

THERAPIST: I see. So, you are pretty stuck in the depression and this unhealthy dynamic. Do you know your daughter is in the other room hiding and wishes you would stand up for yourself?

MARY AS FATHER: (affect changes and eyes become tearful) I know. I don't know how to change this. I feel stuck and I'm afraid of how my depression and my wife's anger will impact Mary.

THERAPIST: What do you want to say to Mary that you never had the chance to?

MARY AS FATHER: Mary, I'm so sorry about all of this. This wasn't the type of house I wanted you to grow up in. I wish I could have been there for you more and I wish I could have provided a safer home.

THERAPIST: Dad, do you know Mary grew up to struggle with depression just like you? What do you want to tell her about depression?

MARY AS FATHER: Mary, it's okay to be depressed. It's not your fault that you have depression - it runs in the family. There is no shame in having a mental health issue. But now you have an opportunity to change this generational pattern and take care of yourself.

THERAPIST: Can you tell Mary what you think about all the work she has been doing to take care of herself lately?

MARY AS FATHER: I'm so proud of you Mary. You are handling your depression in a way that I couldn't.

THERAPIST: Reverse roles. Mary what do you want to say to dad in response?

MARY: (tearful) Thank you dad. I always wanted to hear you say you are proud of me. I can see how much you suffered because of your depression and because of mom. I wish you were more available to me growing up, but I understand what it's like to be stuck in depression. I am going to get better for both of us.

THERAPIST: Reverse roles. Mary, as your father, can you show us how you wish he would have stood up to mom?

MARY AS FATHER: Okay. (turns to role of mom) I'm sorry how my depression impacts you. Regardless, I am not going to allow you to talk to me like that anymore. You are scaring Mary. And just because I am depressed, doesn't make me any less of a man. I have a mental illness and there is no shame in that. Your yelling at me and shaming me doesn't help at all-it only makes things worse. And you clearly have some of your own issues to work out.

THERAPIST: Okay, Mary. Reverse roles with yourself today. What is it that you'd like to say to mom?

MARY: (presents as emotional and unsure about what to say to mom). 
THERAPIST: Mary, take a look around at all of your strengths in the room (pointing to the plant, the painting on the wall, the lamp, the clock, and the pillow-representing compassion, courage, hope, herself in the future, and God).

(As Mary looks around remembering her strengths, she stabilizes emotionally).

THERAPIST: I'm going to offer a doubling statement for you Mary, if it fits you can repeat it. If not, simply change it...

THERAPIST AS DOUBLE: I've never stood up to you before mom, but I'm going to do it today with the support of my strengths.

MARY: Mom, I've never done this before, but today I'm going to stand up to you because I have all these new strengths and supports.

THERAPIST AS DOUBLE: I am so damn angry and upset!

MARY: I am so damn angry and upset at you Mom. You were so mean and abusive to dad and I. Half a century later I am still impacted by your behavior. You were so hard on dad and it wasn't fair. You clearly didn't understand depression or mental illness. Do you think he wanted to be depressed? I grew up believing that it was shameful to have a mental illness because of you. This belief has made it so difficult to ask for help or to tell my friends that I am depressed.

THERAPIST: Mary, choose one of these scarves to represent this belief that it is shameful to have a mental illness.

(she chooses a gray scarf from the therapists' collection of scarves).

THERAPIST: Now, tell mom how this has impacted you and when you are ready, I want you to give it back to her. It sounds like you've been carrying around this belief that you inherited from Mom which hasn't been so helpful.

MARY: See this mom? This is yours, not mine. I'm sick of carrying this around. It has done nothing but make me judge other people, hate myself, and stay stuck. Because of this belief, I've isolated myself from my friends. This is yours-not mine.

(Mary physically places the scarf on the chair representing her mom).

THERAPIST: Mary, take a moment to notice what it feels like to no longer carry this belief around.

MARY: I feel much lighter. That belief has weighed me down for so long. I feel like I don't have to be shameful for my mental illness, or for needing help to work through it.

THERAPIST: Tell your mom how things will be different now that you won't carry this belief any longer.

MARY: Mom, I not going to shame myself for needing help. It's your burden for not understanding mental illness, not mine. You should have educated yourself. I'm not going to carry that burden for your ignorance-or anyone else's. This is a part 
of who I am and if you or someone else can't accept that then I don't want them to be in my life anyways. I wish you would understand.

THERAPIST: Reverse roles. Okay mom, I know you didn't understand mental illness when you were alive, and you were pretty hurtful to Mary and her father. Now that you've died, where are you? What has God said to you about your life?

MARY AS MOM: Well, I am dead and have moved onto the afterlife. I spent some time in purgatory being punished for my sins, but God has forgiven me and I am in heaven now.

THERAPIST: Okay, sounds like you have changed. Now that you have shed the imperfections of character and are in heaven, what would you like to say to Mary?

MARY AS MOM: (tearful) Mary I made many mistakes in my life. Now I can see how hurtful and selfish I was with you and your father. I was really just scared and in a lot of my own pain that I didn't know how to deal with. I hope you can forgive me for not being the best mother and for how I hurt you in my life.

THERAPIST: Reverse Roles. What do you want to say to Mom?

MARY: Mom, you were so angry and abusive to me. I just wanted a loving mom. (Begins to cry) Honestly, I felt relieved when you died because I thought I would be free from the trauma and negativity, but I wasn't. I've been so angry at you and I'm ready to let that go so I can move on and be free (continues to cry). This is the first time I've really felt sad about your death. I wish we could have had a better relationship while you were alive. I still think about you regularly. There were times that you were loving and fun to be around and I cherish those memories. Although you were hurtful, there were also important things you taught me about life which have been helpful. I was so focused on the negative experiences with you that I forgot about the other positive parts of you. I think I can see all of you now.

THERAPIST: Good Mary. As we move towards closure, is there a final statement to say to mom?

MARY: Mom, thank you for the positive things you've taught me. I am going to let go of the negative parts of our relationships so I can move on and be free going forward.

After this final statement, Mary de-roles the scene and the session moves into sharing and processing the experience. Mary shares that she feels exhausted but also much lighter and accomplished. She reports that she was surprised at being able to remember positive memories with mom after expressing her anger and equally surprised at being able to access her sadness at mom's death. She shares about her newfound commitment to taking care of herself and her mental illness after connecting it to the larger generational history and her father. She says that the negative memories of her family dysfunction are still present but that they do not have the same emotional charge that they used to have for her. Mary describes her plan to stop hiding her struggles with mental illness from her friends that she had been 
avoiding and that she plans to trust that they will understand. Finally, she describes her new insight of how her depression and anxiety may have impacted others in her life and that she will use this as increased motivation to take care of herself.

In the case at hand, it is also important to highlight how cultural factors may have impacted the process. The closure with Mom was accessed by conceptualizing a scene based on Mary's spiritual/religious beliefs. When directing a psychodrama, it is essential to enter the reality of the protagonist rather than to instruct the protagonist to enact a scene that is incongruent with their religious or cultural belief system. Similarly, some cultural belief systems might inhibit an individual from psychodramatically expressing anger toward a parent or saying anything that might be seen as disrespectful. There are other creative ways of navigating this such as splitting Mom into two parts - a "good mom" and "bad mom" or seeing if the mother role might offer permission to the protagonist about expressing anger. When directing a protagonist, it is important to consider interventions or suggested actions/scenes that reflect the cultural realities for the protagonist. The trajectory of Mary's psychodrama would look very different depending on her religious/spiritual beliefs as well as her cultural values around family, anger, and parental role relationships.

\subsection{Conclusion}

The sequence of one-to-one psychodrama session with Mary described above shed light on the unique strengths of using psychodrama in individual settings. Although there were no role players, the surplus reality of the psychodrama still offered potentiality for corrective emotional experiences and the renegotiation of both trauma and loss (Giacomucci, 2018, 2020; Giacomucci \& Marquit, 2020; Giacomucci \& Stone, 2019). The continuity of work with Mary would have been much more difficult to achieve in a group setting as the therapist would have also been responsible for the needs of the rest of the group. Though the one-to-one psychodrama process is absent of auxiliary role players, there is still value in engaging in the dramatization. In some cases, the client may be too anxious or concerned with the judgment of others to participate in this level of work within a group setting. Because it was a one-to-one setting, the therapist can meet the client where they are at in each session and tailor the psychodrama to their here-and-now warm-up. The movement from sociometric assessment to strengths-based work, intrapsychic work, and finally interpersonal work portrays a useful route of pacing with a client to create both inner and interpersonal change using Moreno's methods in a safe way. This process moved from the peripheral to the center and back to the peripheral —-from the social to the internal and back to the social. The client was treated as a person within their social environment.

Sociometry and psychodrama interventions can be seamlessly integrated into a social worker's clinical repertoire, especially in the one-to-one context. These depictions of psychodramatic work in individual contexts suggest a natural fit for clinical 
social work practice with individuals encompassing elements of casework, assessment, and intervention. The same one-to-one interventions can be employed in individual teletherapy sessions with clients (see Sect. 13.2). Sociometric and psychodramatic interventions allow the social worker to meet the client where they are while honoring their subjective experience. With these tools, the client is conceptualized within their social atom while exploring both psychodynamics and sociodynamics (Giacomucci, 2019). The importance of relationships is central to both the process and the content of sociometry and psychodrama in one-to-one contexts. The relationship between client and therapist is particularly essential in the one-to-one psychodrama situation.

\section{References}

Aguiar, M. (2019). Spontaneous theater and one-to-one psychodrama. In Z. Figusch (Ed.), From one-to-one psychodrama to large group socio-psychodrama (2nd ed., pp. 124-146). Morrisville, UK: lulu.com.

Antonio, R. (2019). Dramatic action and inter-subjectivity: One-to-one psychodrama with a depressed patient. In Z. Figusch (Ed.), From one-to-one psychodrama to large group sociopsychodrama (2nd ed., pp. 43-70). Morrisville, UK: lulu.com.

Brito, V. C. A. (2019). One-to-one psychodrama: Reflections on the theory and practice of psychodrama with an individual patient. In Z. Figusch (Ed.). From One-to-One Psychodrama to Large Group Socio-psychodrama (2nd ed.) (pp. 15-28). United Kingdom: lulu.com.

Bustos, D.M. (2019). One-to-one psychodrama psychotherapy. In Z. Figusch (Ed.), From one-to-one psychodrama to large group socio-psychodrama (2nd ed., pp. 29-42). Morrisville, UK: lulu.com.

Bustos, D. M. (1979). Psicoterapia psicodramática (Psychodrama psychotherapy). São Paulo: Brasiliense.

Chesner, A. (2019a). Framing creativity. In A. Chesner (Ed.), One-to-one psychodrama psychotherapy: applications and technique (pp. 7-18). New York, USA: Routledge.

Chesner, A. (2019b). Working with role. In A. Chesner (Ed.), one-to-one psychodrama psychotherapy: applications and technique (pp. 51-67). New York, USA: Routledge.

Cukier, R. (2008). Bipersonal Psychodrama: Its techniques, therapists, and clients. São Paulo, Brazil: Author.

Figusch, Z. (2019). From one-to-one psychodrama to large group socio-psychodrama: More writings from the arena of Brazilian psychodrama. United Kingdom: lulu.com

Fonseca, J. (2019). Relationship psychotherapy: A minimalist psychodrama. In Z. Figusch (Ed.), From one-to-one psychodrama to large group socio-psychodrama (2nd ed., pp. 87-111). Morrisville, UK: lulu.com.

Giacomucci, S. (2018). The trauma survivor's inner role atom: A clinical map for post-traumatic growth. Journal of Psychodrama, Sociometry, and Group Psychotherapy., 66(1), 115-129.

Giacomucci, S. (2019). Social group work in action: A sociometry, psychodrama, and experiential trauma therapy curriculum (Doctorate in Social Work (DSW) Dissertations) (p. 124). https://rep ository.upenn.edu/cgi/viewcontent.cgi?article=1128\&context=edissertations_sp2.

Giacomucci, S. (2020). Addiction, traumatic loss, and guilt: A case study resolving grief through psychodrama and sociometric connections. The Arts in Psychotherapy, 67, 101627. https://doi. org/10.1016/j.aip.2019.101627.

Giacomucci, S., Gera, S., Briggs, D., \& Bass, K. (2018). Experiential addiction treatment: Creating positive connection through sociometry and therapeutic spiral model safety structures. Journal of Addiction and Addictive Disorders, 5, 17. https://doi.org/10.24966/AAD-7276/100017. 
Giacomucci, S., \& Marquit, J. (2020). The effectiveness of trauma-focused psychodrama in the treatment of PTSD in inpatient substance abuse treatment. Frontiers in Psychology, 11, 896. $10.3389 \% 2$ Ffpsyg.2020.00896.

Giacomucci, S., \& Stone, A. M. (2019). Being in two places at once: Renegotiating traumatic experience through the surplus reality of psychodrama. Social Work with Groups., 42(3), 184-196. https://doi.org/10.1080/01609513.2018.1533913.

Hirschfeld, B., \& McVea, C. (1998). A Cast of Thousands' working with the five instruments of psychodrama in the therapeutic relationship. Australian and Aotearoa New Zealand Psychodrama Association Journal, 7, 51.

Kim, L. M. V. (2019). Tele and transference in psychodrama psychotherapy. In Z. Figusch (Ed.), From one-to-one psychodrama to large group socio-psychodrama (2nd ed., pp. 82-95). Morrisville, UK: lulu.com.

Knittel, M. G. (2009). Counseling and drama: Psychodrama a deux. Tuscan, AZ: Author.

Moreno, J. L. (1947). Open letter to group psychotherapists. Psychodrama monographs, No. 23. Beacon, NY: Beacon House.

Moreno, J. L., Moreno, Z. T. (1959) Psychodrama second volume, foundations of psychotherapy. Beacon, NY: Beacon House.

Moreno, J. L. (1972) Psychodrama (Vol. 1, 4th ed.). New York: Beacon House.

von Ameln, F., \& Becker-Ebel, J. (2020). Fundamentals of psychodrama. Singapore: Springer.

Yalom, I. D., \& Leszcz, M. (2005). The theory and practice of group psychotherapy (5th ed.). New York, NY: Basic Books.

Open Access This chapter is licensed under the terms of the Creative Commons Attribution 4.0 International License (http://creativecommons.org/licenses/by/4.0/), which permits use, sharing, adaptation, distribution and reproduction in any medium or format, as long as you give appropriate credit to the original author(s) and the source, provide a link to the Creative Commons license and indicate if changes were made.

The images or other third party material in this chapter are included in the chapter's Creative Commons license, unless indicated otherwise in a credit line to the material. If material is not included in the chapter's Creative Commons license and your intended use is not permitted by statutory regulation or exceeds the permitted use, you will need to obtain permission directly from the copyright holder. 